\title{
Low prevalence of Helicobacter pylori in inflammatory bowel disease: association with sulphasalazine
}

\author{
E El-Omar, I Penman, G Cruikshank, S Dover, S Banerjee, C Williams, K E L McColl
}

\begin{abstract}
The prevalence of IgG antibodies to Helicobacter pylori was examined in 110 patients with inflammatory bowel disease (IBD) (63 ulcerative colitis, 47 Crohn's disease) and compared with 100 age and sex matched control patients. The overall prevalence of $H$ pylori seropositivity in the IBD patients was $22 \%$, which was significantly less than that of $52 \%$ in the controls $(p<0.002)$. There was no difference in prevalence between ulcerative colitis and Crohn's patients. The low seropositivity in the IBD patients resulted from a very low prevalence of $10 \%$ in those currently receiving sulphasalazine $(n=40)$ and similarly low prevalence of $7 \%$ in those previously receiving sulphasalazine $(n=30)$. In those receiving olsalazine or mesalazine and who had never had sulphasalazine, the prevalence of seropositivity was $45 \%$. Further studies using ${ }^{14} \mathrm{C}$ urea breath test and microscopy of antral biopsy specimens confirmed that the negative serology in patients receiving sulphasalazine resulted from absence of the infection rather than absence of humoral immune response to it. In six control patients with $H$ pylori infection, a two week course of sulphasalazine $(500 \mathrm{mg}$ four times daily) only caused slight suppression of the ${ }^{14} \mathrm{C}$ urea breath test. In vitro studies failed to show any direct antibacterial effect of sulphasalazine on $H$ pylori. These findings indicate that longterm treatment with sulphasalazine leads to eradication of $H$ pylori infection and that this does not result from a direct antibacterial effect. It may be caused by the drug treating the gastritis and thereby depriving the bacterium of essential nutrients exuded by the inflamed mucosa.

(Gut 1994; 35: 1385-1388)
\end{abstract}

Helicobacter pylori infection is now acknowledged to be the main cause of chronic antral gastritis. ${ }^{12}$ Colonisation of the gastric antrum by the bacterium results in an intense inflammatory reaction by both the humoral and cell mediated arms of the immune response. ${ }^{3}$ Despite this mucosal response the infection persists indefinitely and the factors sustaining the chronic colonisation are poorly understood. Though $H$ pylori infection is largely confined to the mucosa of the antrum and body of the stomach it has been clearly shown to predispose to ulceration of the more distal duodenal mucosa. ${ }^{45}$ This study was originally undertaken to find out if colonisation of the upper gastrointestinal tract by $H$ pylori might also play a part in the pathogenesis of chronic ulcerative diseases further down the gastrointestinal tract, in particular Crohn's disease and ulcerative colitis.

One of the major mechanisms proposed for inflammatory bowel disease is that the mucosal immune system mounts an inappropriate response against normal luminal constituents such as bacteria, components of the diet or other ingested material. ${ }^{67}$ In $H$ pylori infection there is acquisition of mucosa associated lymphoid tissue within the gastric mucosa ${ }^{8}$ and a $B$ cell and $T$ cell mediated immune response against surface proteins on the bacterium. ${ }^{9} 10$ This immune process could cross react with other bacteria in the small or large bowel with antigenically similar surface proteins. $H$ pylori related antral gastritis also causes leakiness of the gastric epithelium to large molecular weight proteins. ${ }^{11}$ Ability of ingested proteins to penetrate the inflamed mucosa and come into contact with mucosa associated lymphoid tissue could also initiate an immune response against them.

To find out if $H$ pylori infection might participate in the pathogenesis of inflammatory bowel diseases, we examined the prevalence of the infection in patients with and without inflammatory bowel disease. In view of the finding of a very low prevalence of $H$ pylori infection in patients exposed to sulphasalazine further studies were done to investigate the effect of this drug on the organism.

\section{Patients and methods}

Venous blood samples for $H$ pylori serology were obtained from 110 randomly selected patients with inflammatory bowel disease (IBD) attending the gastrointestinal outpatient clinic. Sixty three had ulcerative colitis and 47 had Crohn's disease. Details were recorded concerning the duration, extent, and activity of their IBD, current and previous medical treatment, and previous surgery.

Control serum samples were also obtained from 100 age and sex matched patients from whom venous blood was taken for crossmatching by the hospital's blood transfusion service. These patients were from the same catchment area and were admitted for a variety of surgical procedures. Patients admitted with 
TABLE I Percentage seropositivity to $\mathrm{H}$ pylori in patients with ulcerative colitis $\mathrm{v}$ Crohn's disease and in those with active $\mathrm{v}$ inactive disease

\begin{tabular}{llllll}
\hline & \multicolumn{2}{l}{ Type of IBD } & & \multicolumn{2}{c}{ Current activity of IBD } \\
\cline { 2 - 3 } & Ulcerative colitis & Crohn's disease & & Active & Inactive \\
\hline Number & 63 & 47 & 22 & 88 \\
Mean age (y) & $47 \cdot 3$ & $38 \cdot 7$ & & $41 \cdot 3$ & $43 \cdot 9$ \\
Percentage seropositive & 27 & 15 & & 18 & 23 \\
\hline
\end{tabular}

upper gastrointestinal bleeding or perforation were excluded from the control group.

\section{H PYLORI SEROLOGY}

$H$ pylori IgG serology was performed on all specimens using the Helico-G enzyme linked immunosorbent assay (ELISA) kit (Porton, Cambridge). Preliminary studies were performed on serum samples from 44 subjects of known $H$ pylori status from our hospital's catchment area to determine the sensitivity and specificity of the serological test. The $H$ pylori status of these patients had been confirmed by urea breath test and microscopic examination of endoscopic antral biopsy specimens. These preliminary studies showed that using a value of $15 \mathrm{U} / \mathrm{ml}$ or above as positive, the serological test had a sensitivity of $96 \%$ and specificity of $84 \%$. In the actual study the serum samples from the IBD patients and controls were assayed in the same batches.

\section{CONFIRMATION TESTS OF H PYLORI STATUS}

In 24 of the IBD patients who were taking sulphasalazine and who had negative $H$ pylori serology, further tests were performed to confirm whether the negative serology resulted from absence of the infection or from lack of an IgG response to the infection. These patients had either a ${ }^{14} \mathrm{C}$ urea breath test performed alone $(n=18)$ as previously described ${ }^{12}$ or in addition to endoscopic antral biopsy $(n=6)$. The antral biopsy specimen was fixed in formalin and the sections stained with haematoxylin and eosin.

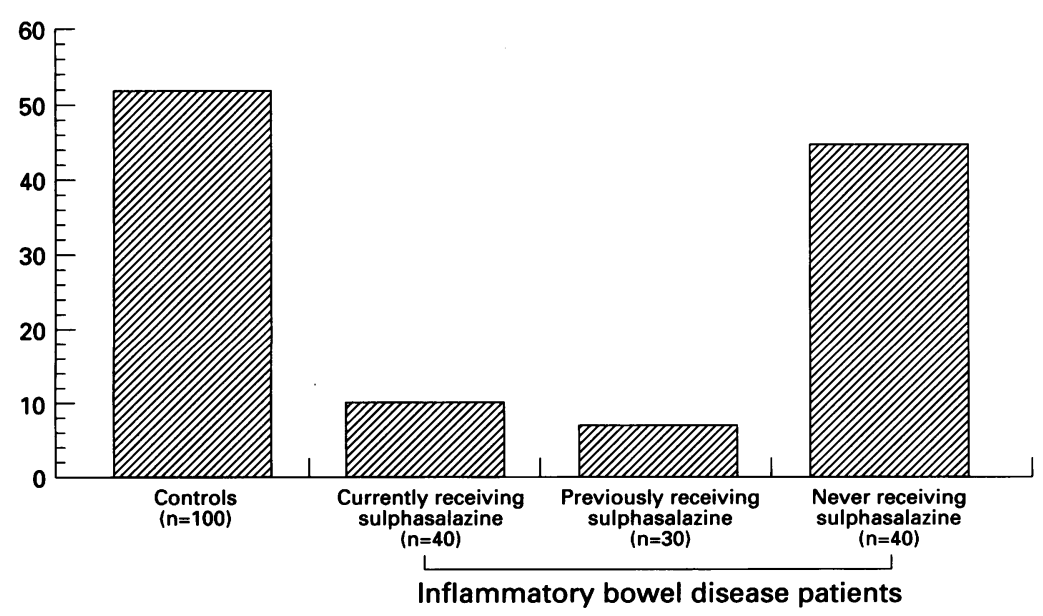

Percentage seropositivity to $\mathrm{H}$ pylori in control subjects and in IBD patients divided on the basis of exposure to sulphasalazine.
IN VIVO AND IN VITRO EFFECT OF

SULPHASALAZINE ON H PYLORI

Six healthy volunteers with $H$ pylori infection had ${ }^{14} \mathrm{C}$ breath tests performed before and on the final day of a two week course of sulphasalazine $500 \mathrm{mg}$ four times daily. The sulphasalazine was taken two hours before their second breath test. Serum samples for $H$ pylori serology were obtained before and on the final day of sulphasalazine treatment. The urea breath test has been shown to be a useful means of assessing the in vivo effects of antibacterial agents on $H$ pylori. ${ }^{13} 14$

The direct antibacterial effect of sulphasalazine and sulphapyridine against $H$ pylori was assessed by standard methods. ${ }^{15} 16$ Five recent isolates of $H$ pylori were incubated in tryptone soya broth supplemented with $10 \%$ horse blood for 72 hours in a microaerophilic atmosphere (BBL Campypak). One $\mu l$ of this culture was transferred to the surface of an antibiotic containing isosensitest agar plate giving a final concentration of about $10^{6}$ colony forming units. Control organisms Staphylococcus aureus (NCTC 6571) and Escherichia coli (NCTC 10418) were included on each plate and plates were incubated for 72 hours at $37^{\circ} \mathrm{C}$ in a microaerophilic atmosphere. The concentration that inhibited at least $80 \%$ of growth was interpreted as the minimum inhibitory concentration (MIC). ${ }^{17}$ The pure drugs were obtained from Sigma Chemical Company Ltd (Dorset, UK) and their in vitro antibacterial effect assessed at concentrations up to $256 \mathrm{mg} / \mathrm{l}\left(\mathrm{MIC}_{90}>256\right.$ $\mathrm{mg} / \mathrm{l})$.

\section{STATISTICAL ANALYSIS}

Assessment of differences between groups was performed using the Mann-Whitney U test. Assessment of changes after sulphasalazine treatment was performed using the Wilcoxon test for paired samples. Patients gave informed consent to participate in the study and the project was approved by the Western Infirmary ethical committee.

\section{Results}

The mean age of the 110 patients with IBD was 42 years (range 14-83) and 52\% were females. The mean age of the 100 control patients was 42 years (range 19-71) and $48 \%$ were females. Using our standard value of $15 \mathrm{U} / \mathrm{ml}$ or above as seropositive, only $22 \%$ of the IBD patients were positive for $H$ pylori compared with $52 \%$ of the controls. The median anti- $H$ pylori IgG titre in the controls was $17 \mathrm{U} / \mathrm{ml}$ compared with $\leqslant 6.25 \mathrm{U} / \mathrm{ml}$ in the IBD patients $(\mathrm{p}<0.002)$. The percentage seropositivity for $H$ pylor $i$ was similar in ulcerative colitis $v$ Crohn's disease patients and in patients with active $v$ inactive disease (Table I).

The low prevalence of seropositivity to $H$ pylori in the IBD patients as a whole resulted from the very low prevalence of $10 \%$ in the 40 patients currently receiving sulphasalazine and of $7 \%$ in the 30 patients previously receiving 
TABLE II Percentage of seropositivity of $\mathrm{H}$ pylori in IBD patients on the basis of exposure to sulphasalazine treatment

\begin{tabular}{llllll}
\hline & & & \multicolumn{2}{l}{ Never receiving sulphasalazine } \\
\cline { 5 - 7 } & $\begin{array}{l}\text { Currently receiving } \\
\text { sulphasalazine }\end{array}$ & $\begin{array}{l}\text { Previously receiving } \\
\text { sulphasalazine }\end{array}$ & $\begin{array}{l}\text { Receiving } \\
\text { mesalazine }\end{array}$ & $\begin{array}{l}\text { Receiving } \\
\text { olsalazine }\end{array}$ & Neither \\
\hline Number & 40 & 30 & 24 & 5 & 11 \\
Mean age & 46 & $46 \cdot 6$ & $38 \cdot 5$ & $30 \cdot 6$ & $38 \cdot 7$ \\
Mean duration of disease (y) & $11 \cdot 4$ & 13 & 3 & $8 \cdot 2$ & $5 \cdot 9$ \\
Percentage seropositive & 10 & 7 & 46 & 40 & 45 \\
\hline
\end{tabular}

sulphasalazine (Figure). Patients who had never received sulphasalazine but who were receiving olsalazine $(n=5)$, mesalazine $(n=24)$ or neither $(n=11)$ had a prevalence of $40 \%$, which was similar to that in the control group without IBD (Table II).

CONFIRMATORY TESTS OF H PYLORI STATUS The ${ }^{14} \mathrm{C}$ urea test was negative in 22 of 24 patients receiving sulphasalazine with negative serology examined. In the six patients who had a ${ }^{14} \mathrm{C}$ urea breath test and microscopic examination of antral biopsy specimens, there was no evidence of $H$ pylori by either test.

EFFECT OF SULPHASALAZINE ON H PYLORI

In vitro - sulphasalazine and sulphapyridine had no bacteriostatic or bactericidal effect against any of the $H$ pylori isolates tested. This included both clinical isolates and NCTC strain of $H$ pylori (11638).

In vivo - in the six $H$ pylori positive healthy volunteers examined their ${ }^{14} \mathrm{C}$ urea breath test remained positive after their two week course of sulphasalazine. The mean 20 minute ${ }^{14} \mathrm{C}$ urea breath test values fell, however, from 246 (range: 180-422) to 196 (range: 135-225) $(\mathrm{p}<0 \cdot 04)$.

\section{Discussion}

This study shows that the prevalence of $H$ pylori seropositivity is much lower in patients with chronic IBD than in an age and sex matched control group. The post hoc analysis of the data collected in the prospective study showed that the low prevalence of $H$ pylori seropositivity in IBD is related to current or previous exposure to sulphasalazine. Several findings in our study confirm that the low $H$ pylori seropositivity associated with sulphasalazine treatment results from the absence of the infection rather than from the drug interfering with the IgG response to the organism. The confirmatory studies of $\mathrm{H}$ pylori status performed in the subgroup of seronegative patients receiving sulphasalazine confirmed absence of the infection. The fact that patients who had stopped receiving sulphasalazine months or years previously also had a low prevalence of $H$ pylori seropositivity provides further evidence against it resulting from the drug suppressing the IgG response.

The explanation for the absence of $H$ pylori in the patients currently or previously receiving sulphasalazine needs to be considered. The prevalence of $H$ pylori infection increases with age and in the Western world roughly equals the age of the patient. ${ }^{18}$ This is shown by our hospital control group with a mean age of 42 years having a prevalence of $52 \%$. The increasing prevalence of $H$ pylori with age is thought to result from the fact that the infection can be contracted at any age and then becomes chronic and persists indefinitely. The very low prevalence of $H$ pylori infection in the patients exposed to sulphasalazine probably result from the infection having been eradicated. If those receiving sulphasalazine had merely been protected from developing the infection then the prevalence would be reduced only by a percentage equivalent to the number of years taking the drug, which was a mean of 12 years. The fact that the patients who had previously received sulphasalazine but were not currently taking it had a very low prevalence of $H$ pylori also shows that their infection had been eradicated rather than merely suppressed.

The mechanism by which sulphasalazine treatment could result in eradication of $H$ pylori is unclear. The in vitro studies using sulphasalazine and its metabolite sulphapyridine failed to show any direct bacterial or bacteriostatic effect. In addition, 14 days of treatment with sulphasalazine only minimally suppressed the ${ }^{14} \mathrm{C}$ urea breath test in the infected healthy volunteers, again showing little evidence of a direct effect of the drug on the bacterium.

One indirect mechanism by which sulphasalazine could lead to eradication of the infection is by its anti-inflammatory properties suppressing the antral gastritis and thus making the gastric mucosa a less hospitable environment for the organism. Exudation of plasma through the inflamed mucosa could provide $H$ pylori with essential nutrients. The mucosal anti-inflammatory properties of sulphasalazine may with time result in suppression of the antral gastritis and thereby lead to eradication of the infection. The small but significant fall in the breath test value at the end of two weeks of sulphasalazine treatment would be consistent with a reduction in density of infection because of some resolution of gastritis. A lowered prevalence of $H$ pylori was not apparent in patients taking pure 5-aminosalicylic acid preparations. Sulphasalazine, however, has been shown to have in vivo anti-inflammatory properties not possessed by 5 -aminosalicylic acid including inhibition of B lymphocytes ${ }^{19}$ and suppression of natural killer cell activity. ${ }^{20}$ Sulphasalazine also exerts its anti-inflammatory effects outwith the large bowel as utilised in the treatment of rheumatoid arthritis.

Another indirect method by which sulpha- 
salazine could eradicate $H$ pylori is by interfering with the adherence of the organism to the gastric mucosa. $H$ pylori is known to bind to specific glycerolipid receptors on the gastric epithelial cells. ${ }^{21}$ Interestingly, sulphasalazine at concentrations present in human plasma has been found to block receptors for bacteria derived peptides on human neutrophils. ${ }^{22}$

In addition to its use in IBD, sulphasalazine is also used as a second line agent in patients with rheumatoid arthritis. In these patients the prevalence of $H$ pylori has been seen to be not so noticeably reduced ${ }^{23}$ and this may be explained by the fact that such patients do not receive it for so long and also all receive the enteric coated preparation, which may lack the local gastric effect. The patients attending our gastroenterology clinic were all prescribed the non-enteric coated preparation. Studies in arthritis patients, however, have noted that those receiving gold treatment have a very low prevalence of $H$ pylori. ${ }^{23}$ The finding that these two main second time anti-inflammatory agents both eradicate $H$ pylori may provide a clue to their mechanism of action against the organism or even a clue to the mechanisms by which they produce their beneficial effect in arthritis. An association between gastrointestinal infection and arthritis has been recognised for many years. ${ }^{24} 25$

The original aim of this study was to find out if there might be an increased prevalence of $H$ pylori infection in patients with IBD and thus evidence supporting a possible role of the infection in the pathogenesis of the bowel disease. Though the reduced prevalence of the infection does not support such a role it also does not refute it. The well established beneficial effects of sulphasalazine in IBD could partly result from it eradicating $H$ pylori and thus preventing the chronic stimulation of the mucosal immune system caused by the infection. The fact that the patients receiving olsalazine or mesalazine who had never had sulphasalazine had a prevalence of $H$ pylori infection similar to the normal controls does not completely exclude a role for $H$ pylori either. It is possible that our patients with IBD all had evidence of $H$ pylori infection on initial presentation and that sulphasalazine has lead to its eradication in nearly all patients treated whereas olsalazine and mesalazine lead to its eradication in only $50 \%$. It will be necessary to examine $H$ pylori status in patients presenting with IBD before commencing any such drug treatment.

In addition to the implications for the immunological basis of IBD and rheumatoid arthritis, our findings are relevant to the treatment of $H$ pylori. Eradication of the infection is an important challenge and it is possible that sulphasalazine might provide a new approach to it, possibly by being given in conjunction with another antibiotic.
This work was supported by a grant from the Glasgow branch of the National Association of Colitis and Crohn's Disease.

This work was presented at the 1992 Autumn meeting of the British Society of Gastroenterology and appeared as an abstract in Gut 1992; 33 (suppl 2) S28.

1 Wyatt JI, Dixon MF. Chronic gastritis - a pathogenetic approach. F Pathol 1988; 154: 113-24.

2 McNulty CAM. Pathogenicity of Campylobacter pylori causative factor in gastritis? Scand $\mathcal{F}$ Gastroenterol 1989; 24 (suppl 160): 3-6.

3 Stacey AR, Hawtin PR, Newell DG. Local immune responses to Helicobacter pylori infection. In Malfertheiner P, Ditschuneit H, eds. Helicobacter pylori, gastritis and peptic ulcer. Berlin: Springer-Verlag, 1990: $162-6$.

4 Marshall BJ, Goodwin CS, Warren JR, Murray R, Blincow ED, Blackbourn SJ, et al. Prospective double-blind trial of duodenal ulcer relapse after eradication of Campylobacter pylori. Lancet 1988; ii: 1437-41.

5 Coghlan JG, Gilligan D, Humphries H, McKenna D Dooley C, Sweeney E, et al. Campylobacter pylori and recurrence of duodenal ulcers - a 12 month follow-up study. Lancet 1987; ii: 1109-11.

6 Podolsky DK. Inflammatory bowel disease (first of two parts). N Engl f Med 1991; 325: 928-37.

7 Sullivan SN. Hypothesis revisited: toothpaste and the cause of Crohn's disease. Lancet 1990; 336: 1096-1097.

8 Wotherspoon AC, Ortiz-Hidalgo C, Falzon MR, Isaacson P. Helicobacter pylori-associated gastritis and primary B-cell gastric lymphoma. Lancet 1991

Crabtree JE, Taylor TD, Wyatt JI, Heatley RV, Shallcross TM, Tompkins DS, et al. Mucosal IgA recognition of Heliocobacter pylori $120 \mathrm{kDa}$ protein, peptic ulceration, and gastric pathology. Lancet 1991; 338: 332-5.

10 Fixa B, Komarkova O, Krejsek J, Nozicka Z, Bures J. Specific cellular immune response in patients with Helicobacter pylori infection. Hepatogastroenterology 1990 37: 606-7.

11 Hopwood D, Milne G, Penston J. Leakiness of gastric superficial and foveolar cell. A quantitative electron microscopic study using tannic acid. F Pathol 1991; 165: 119-24

12 McColl KEL, Fullarton GM, Chittajallu R, El Nujumi AM MacDonald AMI, Dahill SW, et al. Plasma gastrin daytime intragastric $\mathrm{pH}$ and nocturnal acid outut before and at 1 and 7 months after eradication of Helicobacter pylori in duodenal ulcer subjects. Scand $\mathcal{f}$ Gastroentrol pylori in duodenal

13 Graham DY, Klein PD, Opekum AR, Smith KE, Polasan RR, Evans DJ, et al. In vivo susceptibility of Campylobacter pylori. Am $\mathcal{f}$ Gastroenterol 1989; 84: 233-8.

14 Graham DY, Klein PD, Evans DG, Evans DJ, Alpert LC, Opekum AR, et al. Simple noninvasive method to tes efficacy of drugs in the eradication of helicobacter pylor infection. Am F Gastroenterol 1991; 86: 1158-62.

15 Goodwin CS, Blake P, Blincow E. The minimum inhibitory and bactericidal concentrations of antibiotics and antiulcer agents against Campylobacter pyloridis. $\mathcal{f}$ Antimicrob Chemother 1986; 17: 309-14.

16 McNulty CA, Dent J, Wise R. Susceptibility of clinical isolates of Campylobacter pyloridis to 11 antimicrobial agents. Antimicrob Agents Chemother 1985; 28: 837-8.

17 Flores BM, Fennell CL, Holmes KK, Stamm WE. In vitro susceptibilities of Campylobacter-like organism to twent antibiotic agents. Antimicrob Agent Chemother 1985; 28: 188-91

18 Graham DY, Malaty HM, Evans DG, Evans DJ, Klein PD, Adam E. Epidemiology of Helicobacter pylori in an asymptomatic population in the United States. Gastroenterology 1991; 100: 1495-501.

19 Commer SS, Jasin HE. In vitro immunomodulatory effects of sulphasalazine and its metabolites. F Rheumatol 1988; 15: $580-6$.

20 Gibson RP, Jewell DP. Sulphasalazine and its derivatives, natural killer activity and ulcerative colitis. $\mathrm{Clin} S \mathrm{Si} 1985$ 69: $177-84$

21 Lingwood CA, Law H, Pellizzari A, Sherman P, Drumm B. Gastric Glycerolipid as a receptor for Campylobacter pylori. Lancet 1989; i: 238-41.

22 Stenson WF, Mehta J, Spilberg I. Sulfasalazine inhibition of $\mathrm{N}$-formyl-methionyl-leucyl-phenylalaine (FMLP) to its receptor on human neutrophils. Biochem Pharmacol 1984; 33: 407-12.

23 Taha AS, Sturrock RD, Russell RI. Helicobacter pylori and peptic ulcers in rheumatoid arthritis patients receiving gold, sulphasalazine, and nonsteroidal anti-inflammatory drugs. Am $f$ Gastroenterol 1992; 87: 1732-5.

24 Rheumatoid arthritis and the gut. [Editorial.] $B M F 1979 ; 1:$ 1104

25 Pullar T, Hunter JA, Capell HA. Which component of sulphasalazine is active in rheumatoid arthritis? $B M F 1985$; 290: $1535-8$. 